\title{
Influence of expansive additive on formation of fresh polymer modified pastes
}

\author{
Oksana Larsen ${ }^{1, *}$, Marsel Nurtdinov ${ }^{1}$, Viktoria Shvetsova ${ }^{1}$, and Ekaterina Fomina ${ }^{1}$ \\ ${ }^{1}$ Moscow State University of Civil Engineering, Yaroslavskoe shosse, 26, Moscow, 129337, Russia
}

\begin{abstract}
Chemical admixtures are widely used in cement-based mixtures to reduce water demand, increase working time or accelerate strength development. The application of water-soluble polymers in building industry is increasing. The performance of cement mortars and concretes can be improved by the modification of their structure with additives of polymers. The use of polymers in cement-based compositions can decrease the intensity of hydration kinetic and increase the shrinkage deformation. Hardening of polymer-modified cement-based mixtures is associated with drying shrinkage which can significantly decrease crack resistance of cement concretes, especially in the case of polymer dispersions. The influence of polymer admixture with expansive additive on formation of cement-based pastes was investigated. Structure formation of fresh polymer modified cementitious mixtures with expansive additive was experimentally investigated by heat evolution behavior. Structure formation as a function of time and depends from initial mixture design properties such as watercement ratio, polymer-cement ratio and content of expansive additive.
\end{abstract}

\section{Introduction}

Chemical admixtures are commonly used in cement-based mixtures to reduce water demand, increase working time, or accelerate strength development.

Properties of cement-based materials can be improved by addition of a polymer admixtures [1]. Polymer modified mortars have low permeability, good freeze-thaw resistance, relatively higher flexural strength and adhesion strength to old concrete substrate. Such positive properties could be applied in repair materials for concrete buildings, concrete bridges, highway covering materials and waterproof materials [2].

Upon hydration, the resulting hardened material contains a continuous, interconnected matrix of coagulated polymer particles which fill up pores in cement matrix and improve the bonding between aggregates and cement paste.

The addition of polymer frequently modifies the hydration behavior of cement based mortars. It impacts on setting time of the mixture by retardation of the cement hydration. This is especially visible in the compressive strength of the mortar beams.

Latexes such as polyvinyl acetate (PVA) is widely applied in cementitious materials intended for adhesive, repair, and protective applications $[3,4,5]$. Polyvinyl acetate (EVA)

\footnotetext{
* Corresponding author: larsen.oksana@mail.ru
} 
copolymer is a water-redispersible powder or aqueous latex dispersion which can be added to mortar or concrete to improve crack resistance, impermeability and bond strength. [6]. It consists of very small polymer spherical particles $(0.05-5 \mu \mathrm{m})$ and formed by emulsion polymerization and stabilized in water with the aid of surfactants [7].

It is also known, that polymer modified cementious matrixes show a higher shrinkage than the non-modified ones. However, it is also known, that such mixtures show fewer cracks due to shrinkage [8].

Self-desiccation and external drying in cement-based materials result the development of shrinkage-induced tensile stresses that can increase the risk of early-age cracking [9 -13]. To compensate and reduce the shrinkage of concrete the expansive agents are usually used [14]. Hardening of polymer-modified cement-based mixtures is associated with drying shrinkage which much greater than an unmodified. Expansive additives are used to reduce shrinkage deformations which include iron powder, alumina powder $\left(\mathrm{Al}_{2} \mathrm{O}_{3}\right)$, magnesia $(\mathrm{MgO})$, calcium sulfoaluminate (CSA) and calcium oxide $(\mathrm{CaO})$ [15]. According to experimental data [16], the optimal amount of the expanding component in concrete is around $10-15 \%$ by weight of mineral binder. The formation of cement-based materials such as paste, mortar and concrete can be measured by various parameters: early plastic strength of cement paste, ultrasound transmission rate (ultrasonic), heat, temperature, contraction. This process has two periods (Fig. 1):

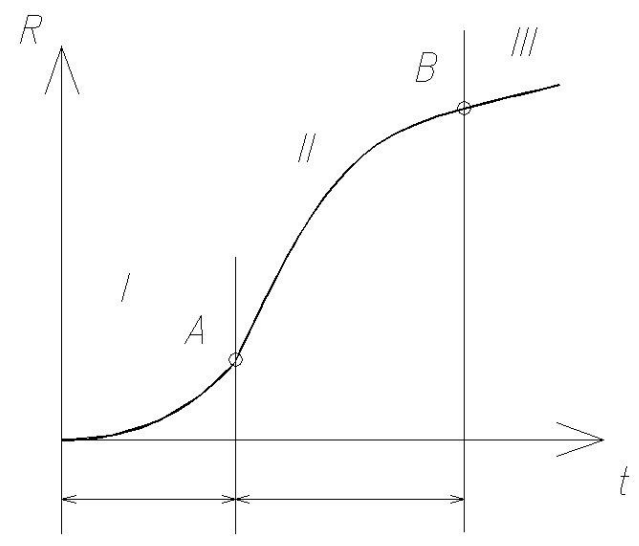

Fig. 1. Estimated periods of structure formation: I - formation of initial structure; II - strengthening of structure; III - stabilization.

While first period the concrete mixture has plastic and thixotropic properties. The time from the beginning of mixing to a sharp increase of strength is called the period of formation of the structure. The section between the first and second period is point $\mathrm{A}$, which determines the moment

of the initial structure of concrete with plastic and thixotropic properties. The change and strengthening of the structure in second period follow the logarithmic law and it allows more accurately predict the properties of concrete in future. In general form the strength of concrete will be described by the equation:

$$
\mathrm{R}=\mathrm{R}_{0}+\Delta \mathrm{R}
$$

where $R_{0}$ - strength of the initial concrete structure; $\Delta R$ - strength of concrete, obtained in process of further hardening and depending on time and temperature, $\Delta \mathrm{R}=\mathrm{f}(\mathrm{t}, \mathrm{T})$. 


\section{Materials and methods}

The influence of expansive additive with polymer admixture on formation of cement-based pastes was investigated.

In this study the ordinary Portland cement CEM I 42,5 N Topkinsky was used. Mineral content was: $\mathrm{C}_{3} \mathrm{~A}=5.6 \%$. Chemical composition was presented with: $\mathrm{Na}_{2} \mathrm{O}=0.6 \%$, $\mathrm{SO}_{3}=3.2 \%, \mathrm{Al}_{2} \mathrm{O}_{3}=4.65 \%, \mathrm{MgO}=1.44$. Standard consistency was equal to $27 \%$ and specific surface area was equal to $3000 \mathrm{~cm}^{2} / \mathrm{g}$.

The investigations were carried out using of polyvinyl acetate water-redispersible powder (PVA). The commercial polymers Vinnapas $5010 \mathrm{~N}$ was produced by Wacker Chemie AG with following characteristics: minimum solids content of $98 \%$, particle size maximum $4 \%$ over $400 \mu \mathrm{m}$ and bulk density of $490-500 \mathrm{~kg} / \mathrm{m}^{3}$.

Expansive additive (EA) is a finely ground mixture consisting of aluminate or sulfoaluminate and sulfate components. It was produced by Consolit and had specific surface area not less than $350 \mathrm{~m}^{2} / \mathrm{kg}$. Chemical composition of admixture consisted: $\mathrm{SO}_{3}=17-25 \%$, alumina $\mathrm{Al}_{2} \mathrm{O}_{3}=19-27 \%$.

At the beginning of experiment the standard consistency and setting time of compositions was determined according to Russian standard by the use of Vicat apparatus. The study of formation was carried out on cement paste cube samples 100x100x100 mm with constant $\mathrm{w} / \mathrm{c}=0.27$. Three different samples were made: a sample without additives (sample 1); a sample with $25 \%$ of PVA by mass of the binder (sample 2); a sample with $25 \%$ of PVA and optimum value with $10 \%$ of expanding additive by mass of Portland cement (sample 3 ) respectively.

\section{Results}

The thermoelectric converters were immediately placed into the cubes from the time of manufacturing to register the temperature during hydration.

This experiment was carried out by device Oven TRM-138, designed to measure, register and regulate temperature, pressure or other physical parameter, simultaneous control of several actuators, as well as to register the measured parameters on a computer (Fig. 2).
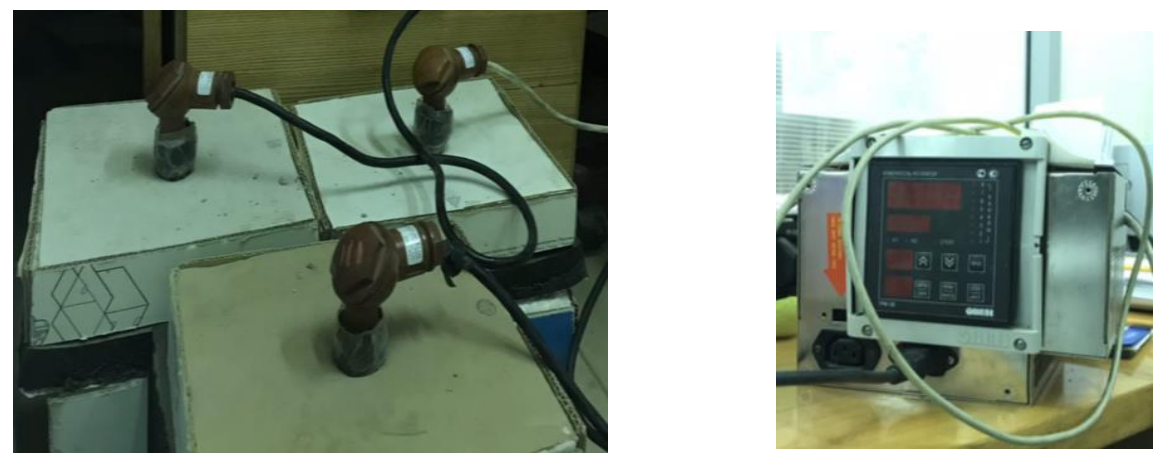

Fig. 2. The device OvenTRM-138 for measuring and register the temperature of the hydration.

The experiment was conducted in adiabatic conditions. The operation of the device is based on transformation of the physical parameters of the object (in our case - temperature) into electrical signals entering the device for further processing (Fig.3). Thermoelectric converters were used for temperature control. The principle of operation of thermoelectric converters is based on the phenomenon of Seebeck, consisting of the appearance of an electromotive force at the ends of two conductors dissimilar in chemical composition when 
heated at the point of their connection. The value depends on the temperature difference between connection point of the conductors and their free ends, as well as on the chemical composition.

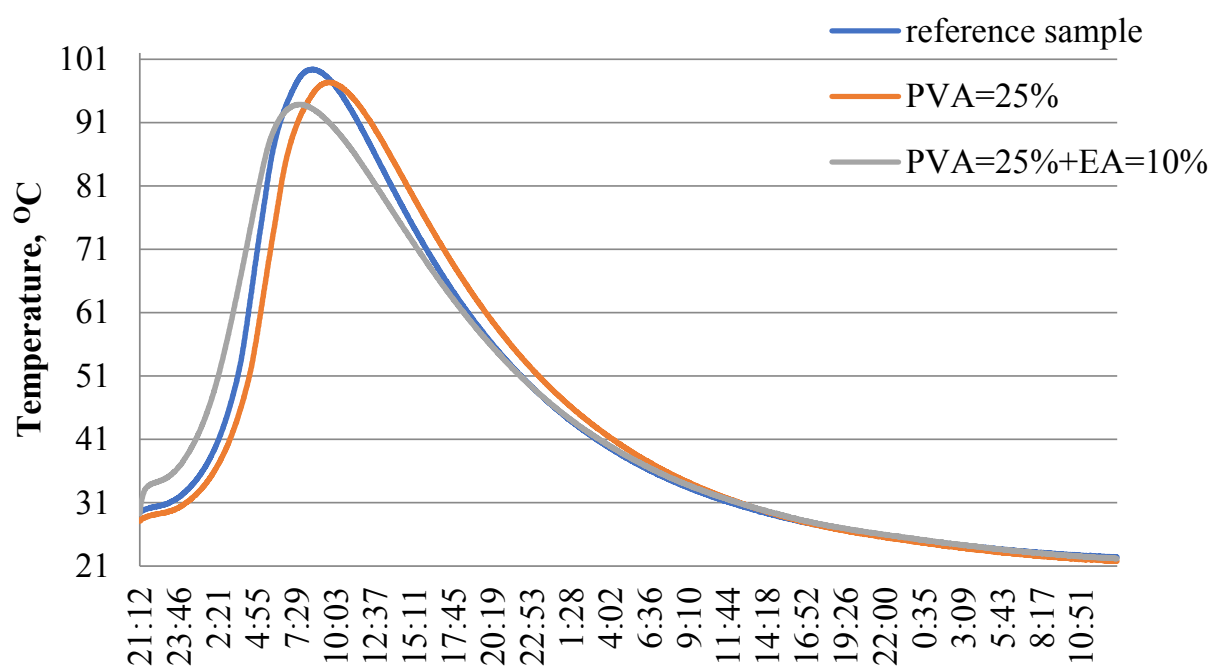

Time, h:min

Fig. 3. The dependence of heat generation from time of hardening.

\section{Conclusions}

The obtained data showed that the polymer-modified cementitious materials with expansive additive reduces the formation period which is most likely associated with ettringite formation. The most intense heating starts at 5.5 hours. The temperature of hardening mixtures rose due to self-heating: a sample 1 without additives up to $99.4{ }^{\circ} \mathrm{C}$; a sample 2 with $25 \%$ of PVA by mass up to $97{ }^{\circ} \mathrm{C}$, a sample 3 with $25 \%$ of PVA and $10 \%$ of expanding additive up to $92{ }^{\circ} \mathrm{C}$. The composition with expansive additive (sample 3 ) had the lowest heat release which is explained by earlier structure formation. According to the obtained data (Fig.3), the initial setting of this mixture was 20 minutes and final setting time 2.5 hours. Based on obtained data it can be concluded that the expansive additive can serve not only to reduce shrinkage deformations, but also to regulate the set of the initial strength of the system. The introduction of the expansive additive reduced the peak heat release of the whole system with a lower maximum hydration temperature, early setting time and higher resistance to thermal expansion. The sample 2 had higher peak of temperatures for 2 hours later and with less heat dissipation compared to ordinary cement paste (sample 1).

\section{References}

1. M. U. K. Afridi, Y. Ohama, M. Zafar Iqbal, K. Demura, Cem. and Concr. Comp., 17, 2 (1995)

2. X.-M. Kong, C.-Ch. Wu, Y.-R. Zhang, J.-L. Li, Constr. and Build. Mat., 38 (2013)

3. M. Wang, R. Wang, H. Yao, S. Farhan, S. Zheng, Z. Wang, C. Du, H. Jiang, Const. Build. Mater., 111 (2016) 
4. R. Wang, D. Ma, P. Wang, G. Wang, Magazine Concr. Res., 67, 18 (2015)

5. C. Issa, J.J. Assaad, Mater. Struct., 50, 28 (2017)

6. A. M. Betioli, P. J. P. Gleize, V. M. John, R. G. Pileggi. Cem. and Concr. Comp., 34, 2 (2012)

7. Joseph Jean Assaad, Constr. and Build. Mat., 163 (2018)

8. Kay A. Bode, Andrea Dimmig-Osburg . J. Eng. Mat., 466 (2011)

9. I. Mehdipour, K.H. Khayat, Cement and Concrete Composites, 92 (2018)

10. S. Nagataki, H. Gomi, Expansive admixtures (mainly ettringite), Cem. Concr. Compos., 20 (1998)

11. L. Mo, M. Deng, A. Wang, Cem. Concr. Compos., 34 (2012)

12. P. Chaunsali, P. Mondal, ACI Mater J., 112 (2015)

13. I.A. Chen, C.W. Hargis, M.C. Juenger, Cem. Concr. Res., 42 (2012)

14. S. Nagataki, H. Gomi, Cem. Concr. Compos., 20 (1998)

15. F. Cao, M. Miao, P. Yan, Constr. and Build. Mat., 183 (2018)

16. M. S. Yelsufyeva, Proceeding of conference Innovation and simulation in construction material science (Tver, 2016) 